\title{
Influence of Aromatic Amine Hardeners in the Cure Kinetics of an Epoxy Resin Used in Advanced Composites
}

\author{
Michelle Leali Costa, Luiz Claudio Pardini, Mirabel Cerqueira Rezende*
}

\author{
Divisão de Materiais, Instituto de Aeronáutica e Espaço, Centro Técnico Aeroespacial, \\ AMR/IAE/CTA, Praça Marechal do Ar Eduardo Gomes n $n^{\circ} 50$, \\ 12228-904 Vila das Acácias, São José dos Campos - SP, Brazil
}

Received: September 28, 2004; Received: January 17, 2005

\begin{abstract}
Composite structures for aerospace applications are mainly made by the well-known prepreg technology. In order to achieve adequate prepreg processing schedules, and consequently maximum fiber strength utilization, one has to know in deep the cure kinetics of matrix, which held the fibers together. This work describes a procedure to study the cure kinetic and has as example how aromatic amine hardeners influence the cure kinetics of an epoxy resin used in advanced composites. The investigation was carried out by using the DSC technique and it was found that depending on the system used the cure kinetics of the formulation obeys order $\mathrm{n}$ or autocatalytic order.
\end{abstract}

Keywords: epoxy resin, cure kinetic, DSC, advanced composites

\section{Introduction}

Structural composites are engineering materials made of oriented reinforcing fibers dispersed in a metallic, ceramic or polymer matrix ${ }^{1}$. The use of composites moved forward in components of aircrafts and space structures due mainly to project flexibility, easy processing, lower density $\left(\sim 2 \mathrm{~g} . \mathrm{cm}^{-3}\right)$, as well as high mechanical strength and modulus. That matcher the requirements of the structures during service ${ }^{2,3}$. This turns the composites particularly attractive as substitutes of the metallic alloys for high demanding aeronautical and space applications.

This work focuses on polymer composites, which are materials made of reinforcing fibers in an embedded polymer matrix. However, the properties of composites depend on other factors, such as the moulding techniques and cure cycles ${ }^{4}$. As a consequence, it is very important that the values of the properties used during the design phase of a certain component consider the process variables, in order to obtain products of high quality and required mechanical strength.

Thus, it is fundamental to know all the parameters involved in the cure cycle. For that, one of the most used techniques in the study of the kinetics of polymerization is the differential scanning calorimetry (DSC). The understanding of the cure kinetics that will delineate the cure cycle to be used in the processing of prepregs is of fundamental importance for good quality advanced composites ${ }^{4}$. The cure kinetics can be followed by using two DSC methods: dynamic and isothermal ${ }^{5}$.

The isothermal method can identify two types of reaction: $n$ order or autocatalytic order ${ }^{6,7}$. If the maximum peak of the isotherm is close to $t=0$, the system obeys kinetics of $n$ order and it can be studied either by dynamic or isothermal methods ${ }^{5,7-9}$. In the case when the maximum peak is formed in between 30 and $40 \%$ of the total time of the analysis, the cure is autocatalytic and it should be studied exclusively by isothermal method ${ }^{5,7-9}$.

The $n$ order model assumes that the reaction obeys the Equation 1:

$$
v=\frac{d \alpha}{d t}=k(1-\alpha)^{n}
$$

where $v$ is the velocity of reaction, $\alpha$ is the reaction rate or conversion rate in a given time $t$. By a linear plotting Equation 1, it is possible to know the values of $n$ and $k$.

Conversely, the autocatalytic model considers independent reaction orders: $m$ and $n$, as shown in Equation 2:

$$
\frac{d \alpha}{d t}=k \alpha^{m}(1-\alpha)^{n}
$$

The parameters $d \alpha / d t$ and $\alpha$ are obtained from DSC isotherms. The reaction rate is obtained by the reaction heat ratio $(d H / d T)$, at a temperat ure $T$, from the total enthalpy $\Delta H_{0}$ (equation 3 ).

$$
\frac{d \alpha}{d t}=(d H / d t) / \Delta \mathrm{H}_{0}
$$

where $\Delta H_{0}$ is the experimental enthalpy corresponding to the total area up to the reaction peak or from the theoretical enthalpy found in the literature.

The value of $\alpha$ is determined by measuring the partial reaction heat at a time $t, \Delta H_{p}$ divided by the total reaction heat is taken from the isothermal reaction, $\Delta H_{i s o}$, (Equation 4)

$$
\alpha=\frac{\Delta \mathrm{H}_{p}}{\Delta \mathrm{H}_{i s o}}
$$

Finally, with a minimum of three isotherms, one can obtain the kinetic parameters $E$ (activation energy) and $A$ (pre-exponential factor) from Arrhenius plots.

Excellent reviews concerning mechanisms and kinetics of thermoset cure are presented in literature ${ }^{4,8,10-13}$. Despite the considerable current research effort in the field of epoxy resin cure, numerous issues have yet to be addressed. There is a number of partially conflicting explanations proposed in recent years for the reaction mechanisms of epoxy system cure, ${ }^{410,13-18}$. This work describes a procedure to study the cure kinetic of polymeric systems and has as example how aromatic amine hardeners influence the cure kinetics of an epoxy resin used in advanced composites. 


\section{Experimental}

\subsection{Materials}

\subsubsection{Polymer resin base}

An epoxy resin of the type diglycidyl ether of bisphenol-A (DGEBA), having commercial name D.E.R. 331 - Dow Chemical Products Ltda, was used as received. This resin is liquid at room temperature, it is bifunctional and have an average molecular mass of 378 g.mol ${ }^{-1}$; an epoxy equivalent weight of 189 and $23 \%$ of epoxy groups. Epoxy resin cures mainly by openning the pendant epoxy group either at room temperature or high temperature, depending on the curing agent used ${ }^{10}$

\subsubsection{Curing agent}

The curing agents used were the diphenyl diaminosulfone (DDS), commercial name HT 976, supplied by Hustman and the 4,4'diamine-diphenylmetane (DDM), code D.E.H.50, supplied by Dow Chemical Products.

DDS is a powdered curing agent, pink color, and have to be melted for use. DDM is provided as brown flakes, and also have to be melted for use. Both curing agents are aromatic amines. Table 1 lists physical properties of DDS and DDM curing agents.

\subsubsection{Preparation of the formulations}

The formulations are prepared by mixing the DGEBA resin in apropriate stoichometric proportions of $30 \mathrm{pph}$ DDS and $27 \mathrm{pph}$ DDM. Then they are heated up to the hardener melting temperature, for approximately $10 \mathrm{~min}$, being soon cooled down in the same interval of time.

\subsubsection{Characterization}

DSC scannings were carried out in a Perkin-Elmer-7 Thermal Analysis System, previously calibrated with indium, under constant flow of nitrogen $\left(100 \mathrm{~mL} \cdot \mathrm{min}^{-1}\right)$ and heating rate of $10{ }^{\circ} \mathrm{C} \cdot \mathrm{min}^{-1}$. The weight of the samples varies from 10 to $15 \mathrm{mg}$. Sealed aluminum pans were used.

For each formulation a scanning was accomplished (Table 2), in which total heat of reaction $\left(\Delta H_{0}\right)$ and isothermal temperatures for kinetic studies were obtained. The isothermal scanning gives the value of the partial heat of reaction $\left(\Delta H_{p}\right)$. Table 2 shows the experimental conditions for obtaining the isotherms for the two formulations under study.

The computer program Isothermal Kinetics, in the central module of the Perkin Elmer equipment, allows the determination of variables related with the cure kinetics of each formulation. This computer software also provides the reaction order that better fits to the resin system under study ${ }^{20}$

\section{Results and Discussion}

Table 3 presents the results of the dynamic runs obtained by DSC of the epoxy systems DGEBA/DDS and DGEBA/DDM. The onset, peak and final temperature taken from the dynamic run have lower values for the DGEBA/DDM system than the DGEBA/DDS system. On the other hand, the total heat of DGEBA/DDM system is higher than DGEBA/DDS system.

For the DGEBA/DDM system the reaction temperatures are lower than for the DGEBA/DDS system. This happens, probably, due to the fact that DDM has a lower melting point in relation to DDS (Table 1), which in turn needs a lower energy to melt and then proceeds the cure reaction. Besides that, there is a different between the relative
Table 1. Properties of the diphenyl diamine sulfone and of the 4,4'diaminediphenylmetane ${ }^{19}$.

\begin{tabular}{lcc}
\hline Curing agent & DDS & DDM \\
\hline Melting point peak $\left({ }^{\circ} \mathrm{C}\right)$ & 175 & 94.0 \\
Weight of active hydrogen & 57 & 49.5 \\
$\left(\mathrm{~g} \cdot \mathrm{mol}^{-1}\right)$ & & \\
Molecular weight $\left(\mathrm{g} \cdot \mathrm{mol}^{-1}\right)$ & 248 & 226 \\
\hline
\end{tabular}

Table 2. Parameters used for obtain of the curves of DSC.

\begin{tabular}{lcc}
\hline DSC Curves & DGEBA/DDM & DGEBA/DDS \\
\hline Dynamic run & $\mathrm{T}_{\text {initial }}=50^{\circ} \mathrm{C}$ & $\mathrm{T}_{\text {initial }}=75^{\circ} \mathrm{C}$ \\
Isothermal run 1 & $\mathrm{T}_{\text {end }}=250^{\circ} \mathrm{C}$ & $\mathrm{T}_{\text {end }}=330^{\circ} \mathrm{C}$ \\
Isothermal run 2 & $100^{\circ} \mathrm{C}$ & $160^{\circ} \mathrm{C}$ \\
Isothermal run 3 & $110^{\circ} \mathrm{C}$ & $170{ }^{\circ} \mathrm{C}$ \\
Isothermal run 4 & $120^{\circ} \mathrm{C}$ & $190^{\circ} \mathrm{C}$ \\
\hline
\end{tabular}

Table 3. Comparison among the dynamic scanning of the formulations DGEBA/DDS and DGEBA/DDM.

\begin{tabular}{lcc}
\hline Dynamic run & DGEBA/DDM & DGEBA/DDS \\
\hline Onset temperature $\left({ }^{\circ} \mathrm{C}\right)$ & 86 & 123 \\
Peak temperature $\left({ }^{\circ} \mathrm{C}\right)$ & 157 & 226 \\
Final Temperature $\left({ }^{\circ} \mathrm{C}\right)$ & 224 & 298 \\
$\Delta \mathrm{H}_{0}\left(\mathrm{~J} \cdot \mathrm{mol}^{-1}\right)$ & -374 & -271 \\
\hline
\end{tabular}

reactivity of the DDS and DDM due to the electron density of two molecules. DDS should be less reactive since the sulfone moiety will pull electron density away from the amine groups, whereas the methane moiety in DDM will not.

It is noticed that the reaction between epoxy resin and DDM has a higher amount of heat released than the one with DDS. This suggests that in the case of prepreg processing the DGEBA/DDM formulation would be more sensitive to the effects of accelerated cure than the DGEBA/DDS formulation. Therefore, in the determination of cure cycles for composite processing, the control of the processing conditions must be much more controlled when using the DDM hardener.

Being known the dynamic run of the DGEBA/DDS and DGEBA/ DDM formulations three specific temperatures were chosen for the isothermal runs. The isothermal temperatures were chosen between the beginning of the reaction $\left(X_{1}\right)$ and peak temperature, because main kinetic events of the reaction occur in that area. Another isothermal run was obtained at a temperature of one fourth distance from the initial temperature and the peak temperature, which gives information on the kinetic order of the studied formulation system ${ }^{5,7,8}$.

Figure 1 shows a DSC curve where maximum evolution of heat, or the maximum reaction rate $(d \alpha / d t)$, occurs at the beginning of the reaction, i.e., at a conversion $\alpha \sim 0$. Therefore, the DGEBA/DDS system obeys $n$ order cure kinetics. The $n$ order kinetics implies that the formulation obeys Equation 1. The order $n$ reaction also describes the shape of the isothermal run (exponential function), as observed in the Figure 1, and gives the necessary data to the study of the reaction mechanism. Thus, the value of $n$ influences the rate of reaction of the formulation, which in turn allows the determination of appropriate cure cycles for composite processing.

Figure 2 exhibits the isothermal run that characterizes the reac- 
tion order from the DGEBA/DDM formulation. It is observed that the maximum heat evolution (the maximum reaction rate $d \alpha / d t$ ) occurs in between 30 and $40 \%$ of the total reaction time, i.e., at a conversion $\alpha \neq 0^{6,21}$. Therefore, the DGEBA/DDM system obeys the autocatalytic cure kinetics.

Autocatalytic cure kinetics implies that the formulation obeys Equation 2. The constant $m$ is related to the autocatalytic concentration of the reaction, i.e., the concentration of hydroxyls groups that are being generated as cure proceeds and the constant $n$ is related to the consumption of epoxy groups. Besides, $m$ influences the initial rate of reaction and controls the symmetry of the curve ${ }^{21}$ and the constant $n$ defines the reaction type, i.e., by the shape of the curve. Thus, the total reaction order $(m+n)$ is obviously higher than order $n$ reaction kinetics. This means that formulations having reaction kinetics of order $n$ and order $(m+n)$ must be treated differently when cure cycles for optimum composite processing schedules are required.

\section{Order $\boldsymbol{n}$ cure kinetics}

Data from Table 3 and results taken from the isotherms of the formulation DGEBA/DDS system allows calculation of the kinetic parameters that are presented in Table 4 . These kinetic parameters were obtained by using the "Isothermal kinetics" software ${ }^{20}$.

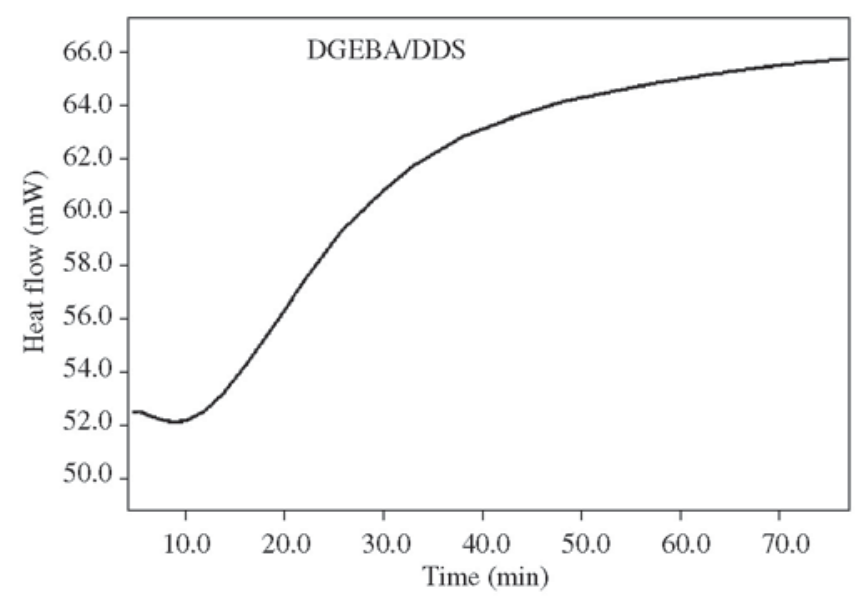

Figure 1. Typical cure isotherms at $170{ }^{\circ} \mathrm{C}$ showing $n$ order reaction mechanism for the system DGEBA/DDS.

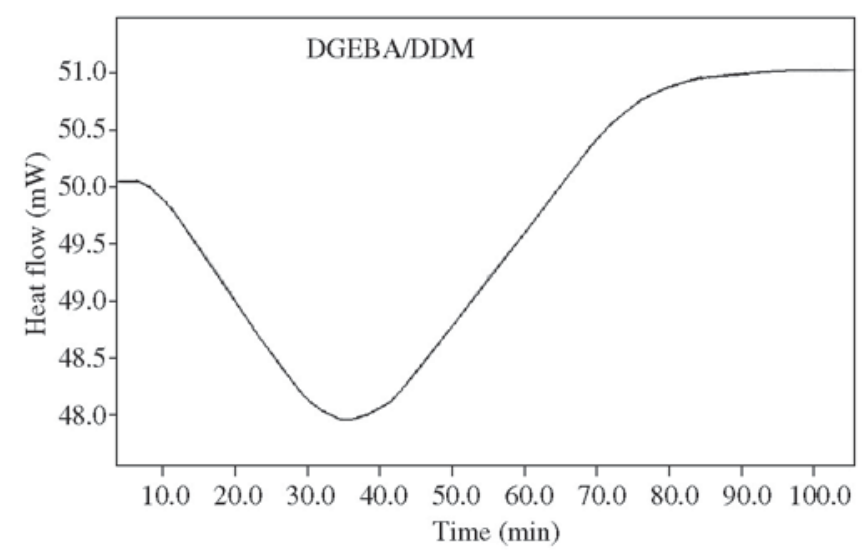

Figure 2. Typical isotherm curve showing autocatalytic mechanism of reaction for the formulation DGEBA/DDM.
It is observed from the results of Table 4 that the value of isothermal $\Delta H$ increases (in module) as isothermal cure temperature goes higher. The increase on isothermal reaction temperature for exothermic reactions generates heat in a higher proportion than the heat generated on the reaction itself.

It is also verified that the Arrhenius constant rate $(k)$ and the reaction order $n$ increases as reaction temperature goes higher. The increase in reaction temperature causes a distinct distribution of molecule speeds (and energies) followed by an increase in the average value of energy from reactant molecules. As a consequence, a larger number of molecules have enough energy, through collision, to surpass the activation barrier and, consequently, the reaction rate may increase $6,22,23$.

The results from isothermal runs allow obtaining the values of the reaction rates and the conversion. Figure 3 shows the reaction rate from each isotherm reaction temperature that was obtained as function of the reaction time for DGEBA/DDS system. There is a maximum of reaction rate for each isotherm reaction temperature. Figure 4 presents the reaction rate $(d \alpha / d t)$ as a function of conversion $(\alpha)$ where it is clear a maximum at $\sim 20 \%$ conversion for all isothermal reaction temperatures. This maximum convertion for the isotherms is related to the mechanisms for both reaction order $n$ and for the autocatalytic reaction order ${ }^{21}$. Therefore, for DGEBA/DDS system, the plots from Figures 3 and 4 confirm the reaction order $n$ previously found.

Plots from Figures 3 and 4, show also that, in general, the $\mathrm{d} \alpha / \mathrm{dt}$ value reaches a maximum at a definite time and/or definite conversion. In the plot of Figure 3 it is verified that temperature has a pronounced influence on the reaction rate. At lower temperatures $\left(\sim 160^{\circ} \mathrm{C}\right)$ the curve has a smaller slope than at higher temperatures and the reac-

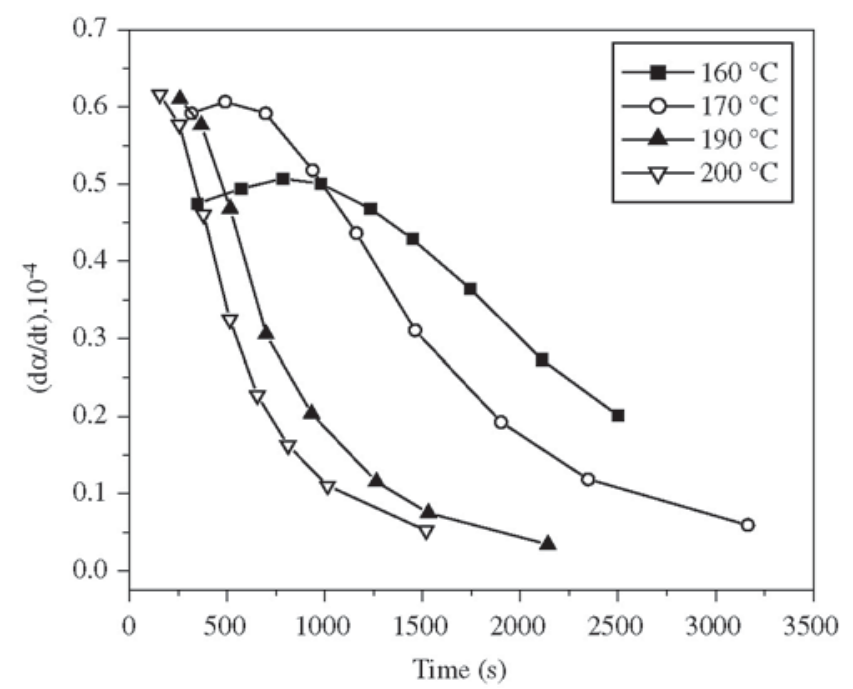

Figure 3. Isothermal reaction rate as a function of reaction time at $160{ }^{\circ} \mathrm{C}$, $170{ }^{\circ} \mathrm{C}, 190^{\circ} \mathrm{C}$ and $200^{\circ} \mathrm{C}$ for the system DGEBA/DDS.

Table 4. Results for isothermal enthalpies $\left(\Delta \mathrm{H}_{\text {iso }}\right)$ and kinetic parameters $(k$ and $\boldsymbol{n}$ ) from the formulation system DGEBA/DDS.

\begin{tabular}{cccc}
\hline $\mathrm{T}(\mathrm{C})$ & $\Delta \mathrm{H}_{\text {iso }}\left(\mathrm{J}_{\mathrm{g}} \mathrm{g}^{-1}\right)$ & $\boldsymbol{k}(\mathrm{T})$ & $\mathrm{n}$ \\
\hline 160 & -194 & $4.50 .10^{-4}$ & 0.38 \\
170 & -224 & $8.99 .10^{-4}$ & 0.58 \\
190 & -260 & $1.43 .10^{-3}$ & 0.78 \\
200 & -280 & $2.01 .10^{-3}$ & 0.96 \\
\hline
\end{tabular}


tion takes more time to reach the maximum conversion rate (d $\alpha / \mathrm{dt})$. At higher temperatures $\left(\sim 190-200{ }^{\circ} \mathrm{C}\right)$ the curve becomes steeper in the beginning of the reaction and reaches the maximum reaction rate. Therefore, at the begining of composite processing, smaller temperatures are desirable once they help an adequate prepreg handling, moulding and cure control. This avoids undesirable fast-uncontrolled reactions, which can compromise quality and properties of the product.

Figure 4 confirms the observations taken from Figure 3. The DGEBA/DDS system has maximum conversion around $15 \%$. According to Equation (1), when conversion $(\alpha)$ is equal to zero, the $k$ (reaction rate constant) value can be found from plots of $d \alpha / d t$ as a function of time or as function of conversion, i.e.:

$$
\frac{d \alpha}{d t}=k \cdot(1-\alpha)^{n},[\text { if } \alpha=0 \text { thus } d \alpha / d t=k] \text {. }
$$

However, from chemistry point of view such consideration is not valid since there is no reaction at a zero conversion, and, therefore, there is no reaction rate constant. Comparing these data with the $k$ values from Table 4 it is verified that both are of the same order of magnitude.

Figure 5 shows the Arrhenius plot ( $\ln k v s$ 1/T) for DGEBA/DDS formulation. The curve represents the activation energy and the value found is $46.4 \mathrm{~kJ} \mathrm{~mol}^{-1}$. According to the literature, chemical reactions have activation energies in between 30 and $100 \mathrm{~kJ}^{-\mathrm{mol}^{-1}}$. The activation energy of very viscous systems is smaller, $10-20 \mathrm{~kJ}^{-\mathrm{mol}^{-1}}{ }^{23}$. Therefore, the value of activation energy for DGEBA/DDS system agreed with the values found in literature ${ }^{24-29}$.

\section{Mechanism of Autocatalytic Cure}

Table 5 shows results for DGEBA/DDM formulation obtained by isothermal reaction runs. The data were calculated by the "Isothermal kinetics" software.

It is observed that, as for the DGEBA/DDM system, the isothermal $\Delta H$, the rate constant and the kinetic exponent $n$ increase proportionally as a function of temperature.. Then, a higher number of molecules acquires enough energy for collision, reaching the reaction activation barrier and, consequently, increasing the reaction rate $e^{6,22,23}$. On the other hand, the kinetic exponent $m$ decreases as temperature increase due to the effect of the thermal catalysis, superseding the

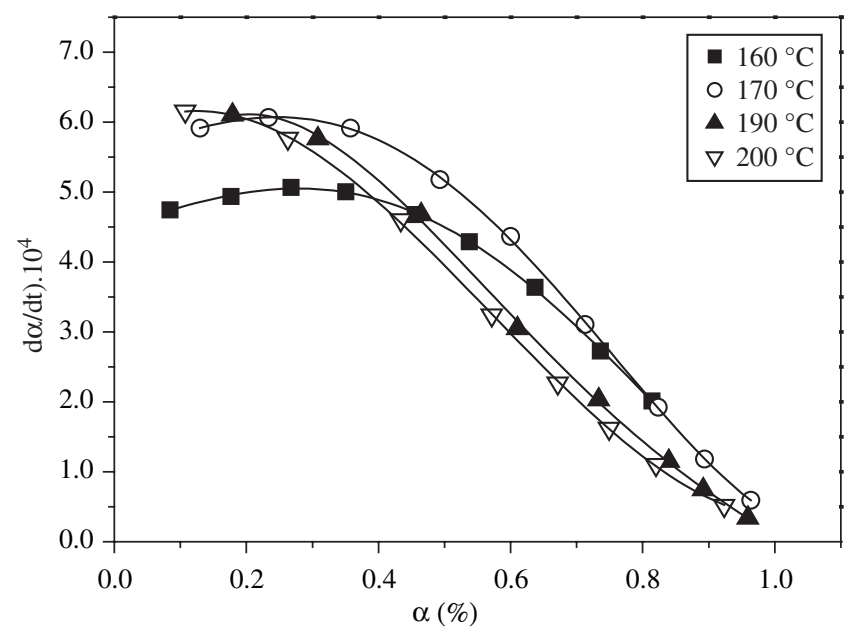

Figure 4. Isothermal reaction rate as a function of the conversion at $160{ }^{\circ} \mathrm{C}$, $170{ }^{\circ} \mathrm{C}, 190{ }^{\circ} \mathrm{C}$ and $200{ }^{\circ} \mathrm{C}$ for the system DGEBA/DDS autocatalytic effect of $m^{21}$. Figure 6 illustrates the variation of $m$ and $n$ with the temperature.

It can be verified in Figure 6 that at $78{ }^{\circ} \mathrm{C}$ the kinetic exponents $m$ and $n$ have the same value $(m=n=1.34)$. This means that at the early beginning of the polymerization reaction, the autocatalytic effect is the same as the thermal effect. On the other hand, the value of $m$ decreases as cure temperature increases, approaching zero when the temperature reaches nearly $226{ }^{\circ} \mathrm{C}$. It should be noted that, a value nearly constant for the total reaction order $(m+n=3)$ is obtained throughout the polymerization reaction, with $n$ corresponding to nearly $75 \%$ and $m$ to $25 \%$ of the total reaction order.

The isothermal reaction rate as function of time obtained for the DGEBA/DDM autocatalytic system is shown in Figures 7 and 8. The conversion $\alpha$ is also shown. Each cure isotherm has a maximum at the $d \alpha / d t$ parameter, which is typical for an autocatalytic mechanism of $n$ order $^{20}$. In this case, the curves are more defined that the ones shown in Figures 3 and 4, according to previous results presented by Seferis ${ }^{21}$.

Figures 7 and 8 also show the influence of the temperature on the reaction rate. The curve obtained at the lowest temperature $\left(100{ }^{\circ} \mathrm{C}\right)$ presents the lowest slope, and the reaction takes longer to reach the maximum conversion rate $(d \alpha / d t)$. As temperature increases $(\sim 110-$ $130^{\circ} \mathrm{C}$ ) the curves become steeper, reaching the maximum reaction rate in a short time. Therefore, in order to get a tight control of the polymerization reaction during composite processing, it is advisable to use lower temperatures in the beginning of the cure cycle. This prevents uncontrolled reactions, which could lead to a composite having poor mechanical properties.

The maximum reaction rate occurs at nearly $45 \%$ of conversion (Figure 8), suggesting that, when the cure reaction reaches its

Table 5. Results of enthalpy of the isotherms $\left(\Delta H_{i s o}\right)$ and kinetic parameters $(k, n$ and $m)$ of the DGEBA/DDM system.

\begin{tabular}{ccccc}
\hline $\mathrm{T}\left({ }^{\circ} \mathrm{C}\right)$ & $\begin{array}{c}\Delta \mathrm{H}_{\text {iso }} \\
\left(\mathrm{J} . g^{-1}\right)\end{array}$ & $\mathrm{k}(\mathrm{T})$ & $\mathrm{n}$ & $\mathrm{m}$ \\
\hline 100 & -347 & $3.79 .10^{-3}$ & 1.64 & 1.17 \\
110 & -372 & $5.21 .10^{-3}$ & 1.76 & 0.97 \\
120 & -375 & $7.67 .10^{-3}$ & 1.89 & 0.96 \\
130 & -380 & $10.2 .10^{-3}$ & 2.02 & 0.88 \\
\hline
\end{tabular}

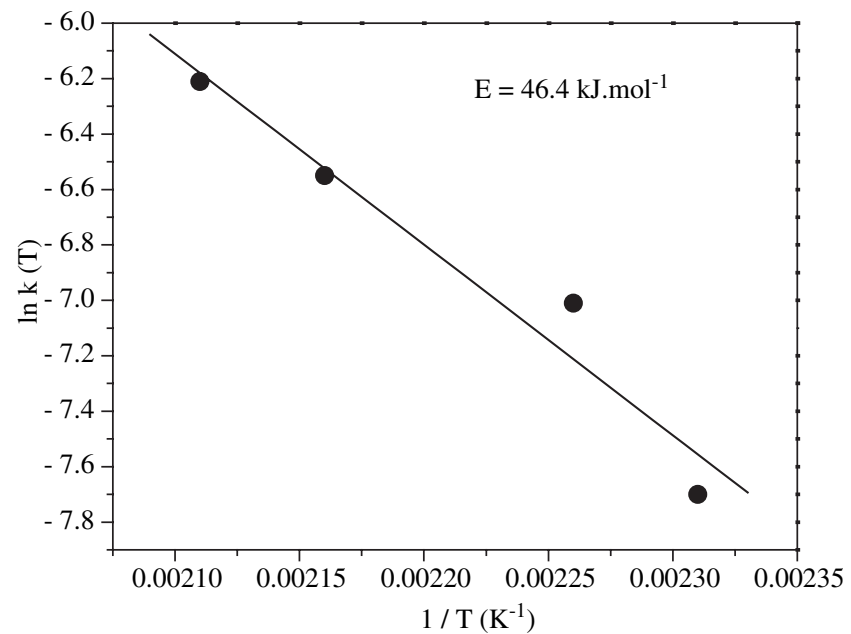

Figure 5. Arrhenius plot of the isothermal reaction rate constants for the DGEBA/DDS systems. 


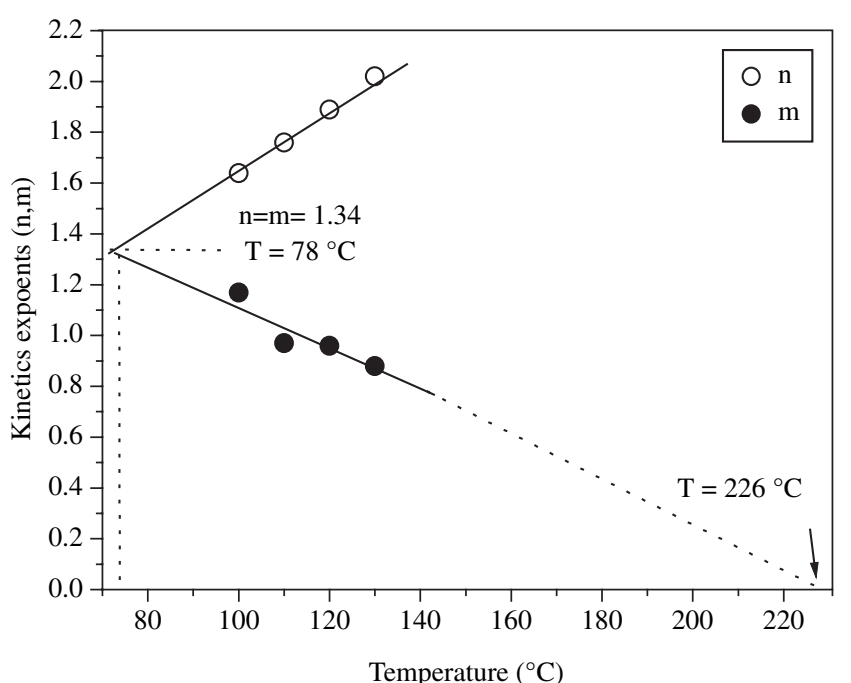

Figure 6. Effect of the temperature on the kinetic expoents $m$ and $n$ of the DGEBA/DDM system.

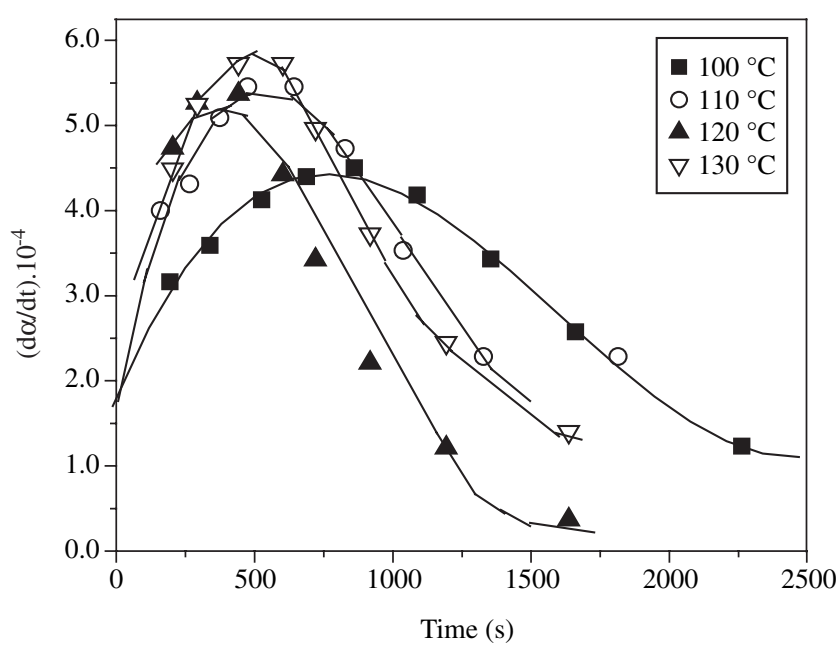

Figure 7. Isothermal reaction rate $v s$. time for the DGEBA/DDM system.

highest conversion rate, $45 \%$ of the total epoxy groups have already been consumed.

Figure 9 shows the activation energy obtained from the slope of the Arrhenius plot of $\ln k$ as a function of inverse absolute temperature $(1 / T)$. The value of $47.2 \mathrm{~kJ} \cdot \mathrm{mol}^{-1}$ was obtained for the activation energy, which is within the range of $30-100 \mathrm{~kJ} \cdot \mathrm{mol}^{-1}$ usually found in the literature ${ }^{23,24-27}$.

\section{Conclusion}

The polymerization temperature for the DGEBA/DDM mixture is lower than for the DGEBA/DDS system. The DDM curing agent has a lower melting point than DDS, and consequently, less energy is required to melt and start the polymerization reaction. Besides that, the relative reactivities of the DDS and DDM curing agent are different due to the differences electron density of two molecules. DDS should be less reactive since the sulfone moiety will pull electron density away from the amine groups, whereas the methane moiety in DDM will not.

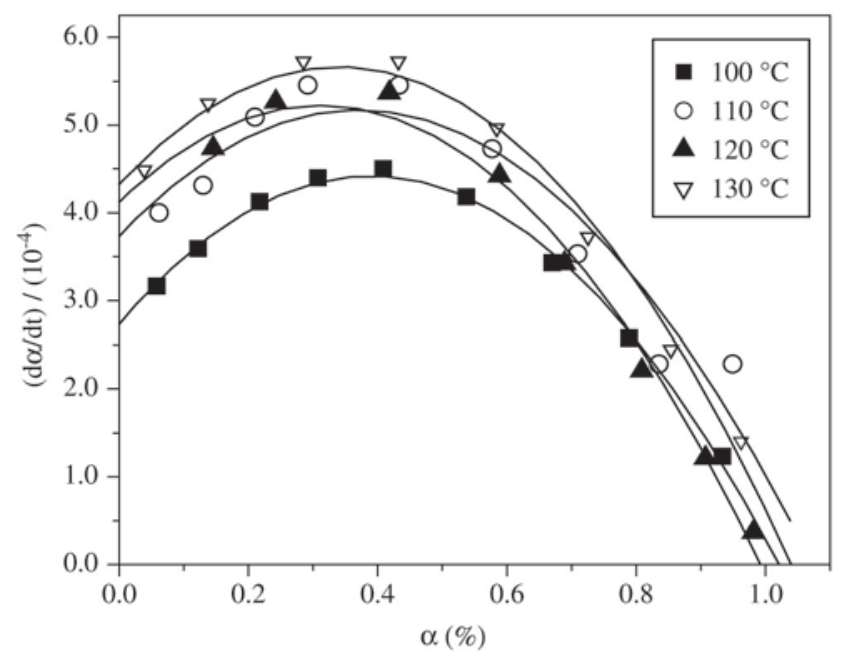

Figure 8. Isothermal reaction rate $v s$. conversion $\alpha$ for the DGEBA/DDS system

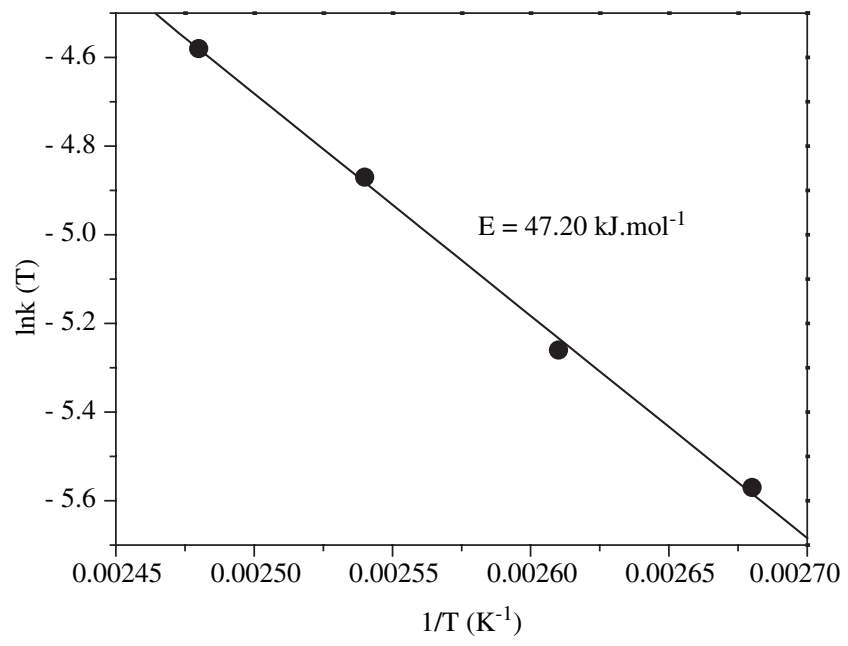

Figure 9. Arrhenius plot for the DGEBA/DDM system.

The DGEBA/DDM formulation has a reaction order $(m+n)$ higher than the DGEBA/DDS formulation and, as a consequence, a higher reaction rate. This means that during the prepreg preparation with DDM is necessary to carry out a very tight control of the cure cycle.

The isotherm shapes are related to the reaction order for each formulation. The well-defined isotherms obtained with the DGEBA/ DDM formulations are characteristics of an autocatalytic reaction. On the other hand, with the DGEBA/DDS formulations the isotherms are formed nearly the zero time, without definition, indicating reaction of order $n$.

The activation energy of both, DGEBA/DDM and DGEBA/DDS reactions, are very close to each other and within the range found in the literature.

\section{Acknowledgments}

The authors acknowledge the financial support received, respectively, from FAPESP under grant 02/01808-7; and CNPq. 


\section{References}

1. Lee S M, editor. International Encyclopedia of Composites, v. 2, $\mathrm{VCH}$ Publishers, New York; 1990.

2. Chou, T W, editor. Polymer matrix composites, in structure and properties of composites, v. 13 Material Science and Technology Series. VCH Publishers, New York; 1993.

3. Engineered Materials Handbook. Vol 1: Composite, USA: Chapman and Hall; 1987.

4. Costa M L. Establishing of process parameters of structural composites by thermal and viscosimetric analyses, São José dos Campos: Instituto Tecnológico de Aeronáutica; 1998.

5. Jang W. A review of DSC kinetics methods. U.S.A: Du Pont Instruments; 1999.

6. Berglund L A. Processing Science for High Performance Thermoset Composites. Sampe Journal. 1991; 27(2):27-37.

7. Costa M L, Rezende M C, Pardini, L C. Métodos de estudo da cinética de cura de resinas epóxi. Polímeros: Ciência e Tecnologia. 1999; 2:37-44.

8. Turi E, editor. Thermal characterization of polymeric materials. Academic Press, USA. 1981.

9. Ozawa T. Journal of Thermal Analyses and Calorimetric. 1970; 2:301311.

10. May CA. Epoxy resins chemistry and technology. Watsonville CA: Marcel Dekker; 1988.

11. Costa M L, Rezende M C, Pardini L C. Estudo da influência do diluente reativo PGE na cinética de cura de resina epóxi utilizada em compósitos estruturais. Química Nova., 2000; 23(3):320-325.

12. Costa ML, Pardini LC, Rezende MC. Avaliação Térmica e Reológica do Ciclo de Cura do Pré-impregnado de Carbono/Epóxi. Polímeros: Ciência e Tecnologia. 1999; 13(3):188-197.

13. Ghaemy M, Riahy MH. Kinetics of anhydride and polyamide curing of bisphenol A-based diglycidyl ether using DSC. European Polymer Journal, 1996; 32(10):1207-1212.

14. Buggy M, Temimhan T, Braddell O. Curing of carbon fibre reinforced epoxy matrix composites. Journal of Materials Processing Technology, 1996; 56(1-4):292-301.

15. Hayes B S, Gilbert E N, Seferis J C. Scaling complications of dual temperature cure resin prepreg systems in airplane part manufacture. Composites:Part A. 2000, 31(7):717-725.
16. Shin DD, Hahn H T. A consistent cure kinetic model for AS4/3502 graphite/epoxy. Composites: Part A. 2000; 31(9):991-999.

17. Varley R J, Hodgkin J H, Hawthorne D G, Simon G P, McCulloch D. Toughening of a trifunctional epoxy system Part III. Kinetic and morphological study of the thermoplastic modified cure process. Polymer. 2000; 41(9):3425-3436.

18. Zvetkov V L. Comparative DSC kinetics of the reaction of DGEBA with aromatic diamines.: I. Non-isothermal kinetic study of the reaction of DGEBA with m-phenylene diamine. Polymer. 2001; 42(16):6687-6697.

19. Basics formulations with epoxy resins Dow. 1987. Dow S/A.. Technical Bulletin p.60.

20. The Perkin-Elmer Corporation. Operating Instruction for the DSC 7 Isothermal Kinetics Software Kit. 1994.

21. Nam J, Seferis J C. Application of the kinetic composite methodology to autocatalytic-type thermoset prepreg cures. Journal of Applied Polymer Science. 1993; 50(9):1555-1564.

22. Byrne C A, Hagnauer G L, Schneider N S, Lenz R W. Polymer Composites. 1980; 1:71.

23. Stutz H, Mertes J, Neubecker K. Lifetime assessment of epoxies by the kinetics of thermal degradation. Journal of Polymer Science. 1993; 91(3):1881-1886.

24. Miranda M I G, Tomedi C, Bica I D, Samios D. A d.s.c. kinetic study on the effect of filler concentration on crosslinking of diglycidylether of bisphenol-A with 4,4'-diaminodiphenylmethane. Polymer, 1997; 38(5):1017-1020.

25. Miranda M I G, Samios D. Analysis And Comparison Of The Barrett, Freeman-Carrol And The Time-Temperature-Transformation (Ttt) Superposition Methods: The Case Of A High Tg Diamine/Epoxy System. European Polymer Journal, 1997; 33(3):325-329.

26. Sykora V, Spacek V, Dobas I. The eighth international symposium on polymer analysis and characterization (ISPAC-8) May 22-24, 1995 Sanibel Island, Florida, USA. Journal of Applied Polymer Science. 1994; 54(9):1385.

27. Souror S, Kamal M R. Differential scanning calorimetry of epoxy cure: isothermal cure kinetics. Thermochimica Acta. 1996; 14(1-2):41-59.

28. Flick E W. Epoxy Resin, Curing Agents, Compounds, and Modifiers an Industrial Guide, second ed. USA: Noyes Publication; 1993. p. 25.

29. Ellis B. Chemistry and Technology of Epoxy Resins. USA: Chapman and Hall. USA; 1993. p. 72. 